\title{
Outcomes of pregnancy-related referrals from rural health facilities to two central hospitals in Harare, Zimbabwe: a prospective descriptive study
}

William Busumani ${ }^{1,2}$ and Paddington T. Mundagowa ${ }^{3 *}$

\begin{abstract}
Background: Between the years 2000 and 2017, the global maternal mortality rate dropped by 38\% however, 94\% of maternal deaths still emanated from low-to middle-income countries. Rural women are at a significantly higher risk of dying from pregnancy when compared to their urban counterparts. Early detection of complications and prompt referral to higher levels of care can reduce the associated maternal and perinatal mortality. This study aimed to determine the maternal and perinatal outcomes of pregnancy-related referrals from rural health facilities to central hospitals in Harare, Zimbabwe.
\end{abstract}

Methods: A prospective descriptive study was conducted using a sample of 206 patients. All mothers who were referred from rural healthcare facilities were recruited for participation. Data were extracted from patient notes using a structured questionnaire and missing information was obtained from the mother after she had recovered. Bivariate analysis was done using IBM SPSS.

Results: The average age of study participants was $27.4 \pm 7.7$ years. $87.4 \%$ had booked for antenatal care and $81.6 \%$ presented to the tertiary facility with their referral notes. The major reasons for referring patients were previous cesarean section (20.4\%) and hypertensive disorders in pregnancy (18.4\%). There were nine maternal deaths thus a case fatality rate of $4.4 \%$ while the perinatal mortality rate was 151/1000 live births. Young mothers were at a higher risk of having adverse perinatal outcomes while primiparous mothers were more likely to have a blood transfusion. Mothers who traveled for $>100 \mathrm{~km}$ to the tertiary facility and those who did not attend any antenatal visit were more likely to need blood transfusion. Delivering at the rural health facility was significantly associated with receiving a blood transfusion at the tertiary facility. Mothers who did not attend antenatal visits were more likely to have negative perinatal outcomes.

Conclusion: The proportion of obstetric patients being referred from rural facilities to tertiary institutions for complications reveals how primary and secondary healthcare facilities in Zimbabwe are falling short of offering the services they should be offering. Equipping these facilities with skilled human resources as well as contemporary equipment could help decongest the central hospitals consequently reducing the adverse maternal and perinatal outcomes.

Keywords: Pregnancy, Referral system, Maternal outcomes, Perinatal outcomes

\footnotetext{
* Correspondence: mundagowap@africau.edu

${ }^{3}$ Clinical Research Centre, Africa University, $132 \mathrm{H}$. Chitepo Street, Mutare, Zimbabwe

Full list of author information is available at the end of the article
}

C C The Author(s). 2021 Open Access This article is licensed under a Creative Commons Attribution 4.0 International License, which permits use, sharing, adaptation, distribution and reproduction in any medium or format, as long as you give appropriate credit to the original author(s) and the source, provide a link to the Creative Commons licence, and indicate if changes were made. The images or other third party material in this article are included in the article's Creative Commons licence, unless indicated otherwise in a credit line to the material. If material is not included in the article's Creative Commons licence and your intended use is not permitted by statutory regulation or exceeds the permitted use, you will need to obtain permission directly from the copyright holder. To view a copy of this licence, visit http://creativecommons.org/licenses/by/4.0/ The Creative Commons Public Domain Dedication waiver (http://creativecommons.org/publicdomain/zero/1.0/) applies to the data made available in this article, unless otherwise stated in a credit line to the data. 


\section{Background}

Despite the fall in the global maternal mortality ratio (MMR) by nearly $44 \%$ from an average MMR of 385 maternal deaths per 100,000 live births in 1990 to an estimated average of 216 maternal deaths per 100,000 live births in 2015 [1], the global maternal death rate is still unacceptably high. While the world celebrated a 38\% drop in MMR between the years 2000 and 2017, the low and lower-middle-income (LMICs) were still reeling under a disproportionate burden of shouldering $94 \%$ of all global maternal deaths [2]. The differences in regional maternal death rates reflect inequalities in access to health services and reveal the underlying gap between the rich and the poor.

Although most of the pregnancy and childbirth complications are unpredictable, they are preventable or treatable. Nearly $75 \%$ of all maternal deaths can be attributed to severe bleeding (post-childbirth), infections (post-childbirth), preeclampsia and eclampsia, complication of delivery as well as unsafe abortions [3]. High maternal and perinatal mortality rates in LMICs can be attributed to three delays [4]. The first delay entails the time taken to recognize danger and making the decision to seek care, the second delay includes time taken in reaching the appropriate facility and the third delay is the time taken in receiving quality care once the woman reaches the healthcare facility. A functional referral system is critical in addressing the second and third delays.

The capacity to deal with the unpredictable complications of pregnancy and childbirth at the primary level of care is limited due to the lack of skilled human resources and facilities hence the need to refer patients to higher levels of care. Key requisites for successful maternity referral systems in developing countries include a referral strategy informed by the assessment of population needs and health system capabilities, a well-resourced referral center, good collaboration between referral levels, formalized communication, and transport arrangements between peripheral and referral centers. Furthermore, an effective referral system has agreed upon area-specific protocols for referrer and receiver, supervision and accountability for provider performance, affordable service costs, the capacity and ability to monitor effectiveness, and policy support $[5,6]$.

Rural-urban health inequities result from weaker health systems and adverse social and environmental determinants experienced by the poor living in rural areas [7]. A study conducted in Zambia reported that women from remote and poorest districts of the country only attended a single antenatal clinic (ANC) visit even when the facilities were closer to their homes because of inadequate staff and low quality of services at these facilities [8]. The same study also cited that women's livelihoods such as the nomadic lifestyles and household chores influenced maternal decision to go for subsequent ANC attendance after the first visit. Another study noted that punitive measures imposed on women by the health workers and/or incentives provided by the nongovernmental organizations prompted women to attend ANC only once [9].

In 2017, Zimbabwe was ranked among the 15 countries that were considered to be 'very high alert' or 'high alert' with MMRs ranging from 31 to 1150 on the Fragile States Index [2]. Maternal mortality in Zimbabwe remains pervasive and some women opt for community delivery due to negative labels attached to health facilities [10]. Such labels include exorbitant costs of services, poor attitudes of health providers, extended waiting times, and geographical barriers like long distances between residences and health facility. Rural women are at a significantly higher risk of dying from pregnancy when compared to women living in urban settings [11, 12]. The MMR in Zimbabwe shows an intolerably high and oscillating trend from 694 maternal deaths per 100,000 live births in 1999 [13], 729 in 2009 [14], 614 in 2014 [15] to 650 in 2016 [16]. The fluctuating national trend suggest a deficiency of sustainable solutions to the problem which is most prominent in rural settings.

The rural health center offers the basic emergency obstetric care package and is the first line of healthcare services for the pregnant woman. In Zimbabwe, all eight rural provinces have provincial hospitals which are supported by district and mission hospitals as well as primary care facilities. According to the World Health Organization (WHO) levels of obstetric care, the district, provincial and central hospitals are all level 2 health centers, and these act as referral centers for the primary healthcare facilities. Besides referrals from rural institutions, the central hospitals in Harare also has urban health facilities that refer complicated obstetric cases, but for this study, only referrals from the rural provinces were considered.

The majority (67\%) of Zimbabweans live in rural areas [17] where it is difficult to access and afford healthcare services. Approximately $23 \%$ live within 5 to $10 \mathrm{~km}$ and $17 \%$ reside more than $10 \mathrm{~km}$ from the nearest health center [14] while some have to walk between 10 and 50 $\mathrm{km}$ to access the nearest health facility [18]. The deficiencies of professional skills, medical supplies, and equipment particularly in the rural parts of the country limit the health workers' options to provide care and treatment $[19,20]$, thus the need to refer complicated cases to higher levels of care.

Rural healthcare facilities in the Northern Region of the country refer their complicated pregnancy-related cases to two central hospitals namely Harare Central Hospital and Parirentyatwa Group of Hospitals. A preliminary review of maternal mortality registers revealed that during the first quarter of 2017, Parirenyatwa Group 
of Hospitals recorded a total of 24 maternal deaths and $13(54 \%)$ of these were patients referred from rural health facilities outside the city of Harare. Although there are guidelines to regulate the referral pathway for the potentially life-threatening pregnancy-related complications, this channel was poorly utilized in Zimbabwe with little to no information being given on communicating transfers and giving feedback. A local study on the effectiveness of the referral system for antenatal and intrapartum problems reported that health professionals failed to comply with the referral system recommendations [21]. Thus, there is limited empirical evidence on the outcomes of pregnancyrelated referrals from rural health facilities to various tertiary facilities. It was also not clear whether referring obstetric patients from primary health centers, district, and provincial institutions can improve the pregnancy-related outcomes.

The quality of obstetric care provided by facilities can be assessed using either process indicators like the referral system or outcome indicators like the maternal mortality ratio [22]. This study aimed to determine the outcomes of pregnancy-related referrals to Harare Central Hospital and Parirenyatwa Group of Hospitals from rural health facilities outside Harare. Establishing the outcomes of the pregnancy-related referrals would help in understanding the lived experiences of patients on emergency referrals to the two central hospitals targeting improving and sustaining the referral pathway while enhancing pregnancy outcomes.

\section{Methods}

\section{Research design}

This was an open prospective descriptive study that used a quantitative design.

\section{Study setting}

Zimbabwe has 10 administrative provinces (eight rural and two urban). The eight rural provinces have 64 administrative districts and 44 district hospitals. According to the Zimbabwe National Health Strategy (2016-2020), there were a total of 1429 primary health centers in 2015. Referring patients to the central hospitals is based on a zoning system with Harare Central Hospital receiving referrals from Mashonaland East Province while Parirenyatwa Group of Hospitalsreceives referrals from Mashonaland West and Central Provinces. These two tertiary institutions are the busiest public health service centers in Zimbabwe. High-risk pregnancies identified at district and provincial hospitals and cannot be managed at that level are referred to the two tertiary hospitals for further care.

\section{Study population}

The study population was made up of an exhaustive sample of all women who were beyond 20 weeks pregnant and up to 6 weeks post-delivery or miscarriage regardless of the pregnancy outcome. These women were referred to the two central hospitals from a rural health facility during the study period. The enrolled women presented at the two central hospitals for management of complications of pregnancy, labor, delivery, or puerperium. Although the two central hospitals used as study sites in this study also received patients from the public and private health institutions within Harare, study participants were mothers referred to the two central hospitals from the surrounding rural health centers during the period 1 December 2017 to 28 February 2018. Thus, women referred from health facilities within Harare were excluded. Depending on the reason for referral, the mother-baby dyad whose information was used in this study wasstable, seriously or terminally ill, or deceased.

\section{Sample size and sampling procedure}

According to a study on the effectiveness of maternal referral system in a rural setting in Tanzania, 12\% of women were referred to a tertiary hospital due to obstetric historical risks [23]. Using Fisher's formula and assuming that $12 \%$ of women were referred due to obstetric historical cesarean section, at a $95 \%$ confidence interval and a level of significance of 0.05 , the calculated minimum number of participants was 163 . The researchers used a census of all the women that presented at the two central hospitals as referrals from rural healthcare centers.

\section{Data collection and analysis}

The study participants were identified by reviewing all women admitted at the obstetrics and gynecological units at the two central hospitals. A structured questionnaire was used to extract information from the patient's registers as well as case notes while missing details were obtained from the health workers who accompanied or were managing the patient. If some of the information was still missing, it was sought from the survivors after they had been stabilizedand certified to be fit for interviewing by their physician. This was done by the principal investigator and two trained research assistants. Confidentiality was maintained by using patient codes and the database was kept personal password-protected computer only accessible to the principal investigator.

Data were entered and cleaned using Microsoft Excel before it was exported IBM SPSS statistical data editor version 20 for analysis. Frequency and crosstables were produced for the demographic and clinical variables as well as for the underlying causes. The researchers 
conducted the bivariate analysis at a 95\% confidence interval for factors potentially associated with pregnancy-related referrals using need for blood transfusion, need for ICU admission, perinatal outcomes and maternal outcomes as dependent variables.

Written informed consent was sought from all study participants and if the participant deceased on the way to the hospital or died before recovering, consent was obtained from the surviving spouse or the hospital medical superintendent. All obtained information was treated with confidentiality. Permission to carry out the study was sought and obtained from Harare Central Hospital and Parirenyatwa Group of Hospital authorities while ethical clearance was obtained from The Joint Research Ethics Committee and Medical Research Council of Zimbabwe (MRCZ/B/1378).

\section{Definition of terms}

\section{Booked pregnancy}

Pregnant women registered for follow-up pregnancymonitoring visits at a particular health facility.

\section{Stillbirth}

A baby having no signs of life at birth.

\section{Early neonatal deaths}

Deaths occurring during the first 7 days of life.

\section{Maternal death}

A death that occurred at any time between admission for labor and delivery and day 42 post-partum.

\section{Referral}

Transfer of a woman from a rural healthcare facility (primary care center, district hospital, or provincial hospital) to which she was booked or admitted for labor and delivery to a facility providing a higher level of care which was a central hospital.

\section{Results}

\section{Demographic characteristics}

A total of 206 women referred to the two tertiary hospitals in Harare from surrounding rural health facilities with pregnancy-related complications were recruited. The mean age of the women was $27.4 \pm 7.7$ years. The mean years spent in formal education was $9.2 \pm 3.3$ years and the median parity was 1 . Table 1 shows the demographic profile of the study participants.

\section{Characteristics of referrals}

Approximately $38.3 \%(n=79)$ of women were referred during the antenatal period, $41.3 \%(n=85)$ during intrapartum period, $18 \%(n=37)$ during the post-partum period while $2.4 \%(n=5)$ had a miscarriage. Most of the women $87.4 \%(n=180)$ had booked their pregnancies and the median ANC visits was $2(\mathrm{SD}=0.95) .61 .7 \%$ $(n=127)$ delivered by cesarean section. $15.5 \%(n=32)$ required blood transfusion, while $5.3 \%(n=11)$ required intensive care unit (ICU) admission. Most women, 78.6\% $(n=162)$ delivered at the two central hospitals, while $16.5 \%(n=34)$ had delivered either at the district or provincial hospital while 3.9\% $(n=8)$ delivered at home.

More than half of the referrals, $55.8 \%(n=115)$, were from Mashonaland West Province while 27.2\% $(n=56)$ were from Mashonaland East Province, 10.7\% $(n=22)$ from Mashonaland Central Province, and 6.3\% $(n=13)$ were from other provinces. After stratifying according to referring districts, a total of 27 districts referred the women with suspected pregnancy complications to either Harare Central Hospital or Parirenyatwa Group of Hospitals with the Mashonaland West Province's Chegutu 19.9\% $(n=41)$ and Zvimba $14.6 \%(n=30)$ Districts having the majority of referrals. $61.2 \%(n=126), 30.1 \%$ $(n=62)$ and $3.4 \%(n=7)$ were referred by a doctor, midwife and clinical officer, respectively. About 3.4\% $(n=7)$ were referred by a registered nurse and $1.9 \%(n=4)$ were self-referrals. More than four-fifths of the patients $(81.6 \%, n=168)$ had referral notes while two-thirds $(61.7 \%, n=127)$ traveled more than $100 \mathrm{~km}$ from the referral centers with $24.3 \%(n=50)$ traveling for more than $2 \mathrm{~h}$ to arrive at the central hospital. Most women, $(88.3 \%, n=188)$ experienced no delay. The most significant delay was the first delay, $(n=10)$ followed by the

Table 1 Socio-demographic characteristics of the mothers referred from a rural health care facility to the central hospita

\begin{tabular}{lll}
\hline Variable & $\begin{array}{l}\text { Demographic } \\
\text { characteristics }\end{array}$ & $\begin{array}{l}\text { Frequency, } \\
\mathbf{n}(\%)\end{array}$ \\
\hline $\begin{array}{l}\text { Age group (completed } \\
\text { years) }\end{array}$ & $<20$ & $42(20.4)$ \\
& $20-34$ & $121(58.7)$ \\
Marital status & $>34$ & $43(20.9)$ \\
& Single & $13(6.3)$ \\
& Married & $189(91.7)$ \\
& Widowed & $2(1.0)$ \\
Religion & Divorced & $2(1.0)$ \\
& Pentecostal & $155(75.2)$ \\
& Apostolic & $45(21.8)$ \\
& Traditional & $5(2.4)$ \\
Parity & Muslim & $1(0.5)$ \\
& 0 & $69(33.5)$ \\
Formal education (years in & 0 & $137(66.5)$ \\
school) & $1-7$ & $13(6.3)$ \\
& $8-11$ & $47(22.8)$ \\
& $>11$ & $133(64.6)$ \\
& & $13(6.3)$ \\
\hline
\end{tabular}


third delay, $(n=8)$. The third delay was mostly caused by lack of blood, $(n=4)$ and lack of skills on the part of the health worker $(n=4)$.

\section{Reasons for referring patients}

Table 2 shows the reasons for being referred from the rural facility to the central hospital.

\section{Maternal and perinatal outcomes}

Maternal morbidity was caused by hypertensive disorders $(6.8 \%, n=14)$, sepsis $(5.8 \%, n=12)$, anemia $(5.3 \%$, $n=11)$ and vesico-vaginal fistula $(1 \%, n=2)$. There were nine maternal deaths recorded during the study period and the case fatality rate (CFR) was $4.4 \%$. Maternal mortality was caused by post-partum hemorrhage $(n=2)$, eclampsia $(n=2)$, post-abortal sepsis $(n=1)$, ectopic pregnancy $(n=1)$, peri-abortal hemorrhage $(n=1)$, ruptured uterus $(n=1)$ and advanced breast cancer $(n=1)$. Fetal outcomes showed that $82.6 \%(n=170)$ were livebirths, $10.7 \%,(n=22)$ were stillbirths and $3.4 \%(n=7)$ were early neonatal deaths. Thus, the perinatal mortality rate was 151/1000 live births.

\section{Factors associated with outcomes of pregnancy-related referrals from rural health facilities to two central hospitals in Harare}

A chi-square test for association was performed between the outcome variables (need for blood transfusion, ICU bed as well as maternal and perinatal outcomes) and independent variables (socio-demographic information and health system-related factors). Table 3 shows the socio-demographic factors associated with pregnancyrelated outcomes while Table 4 shows the health system-related factors associated with pregnancy-related outcomes.

Table 2 Top ten reasons for referral

\begin{tabular}{ll}
\hline Reason for referral & Frequency, $\mathbf{n}(\%)$ \\
\hline Previous cesarean section & $42(20.4)$ \\
Hypertensive disorders of pregnancy & $38(18.4)$ \\
Obstructed labor & $20(9.7)$ \\
Mal-presentation & $14(6.8)$ \\
Antepartum hemorrhage & $12(5.8)$ \\
Obstetric sepsis & $11(5.3)$ \\
Post-partum hemorrhage & $8(3.9)$ \\
Eclampsia & $7(3.4)$ \\
Post-dates & $6(2.9)$ \\
Fetal distress & $6(2.9)$ \\
Other & $42(20.4)$ \\
\hline
\end{tabular}

\section{Discussion}

The role of modern maternity care is to ensure safe maternal and fetal outcomes during childbirth. This study sought to determine the outcomes of pregnancy-related referrals to Harare Central Hospital and Parirenyatwa Group of Hospitals from rural health facilities outside the city of Harare. Understanding the characteristics of referrals, the current operation of the referral pathway could be used to craft interventions towards the reduction of maternal and perinatal mortality in the area under study.

A maternal age of less than 20 years was associated with adverse perinatal outcomes (mortality), a finding that was similar to other studies $[24,25]$. This could be due to failure to achieve the minimum number ANC visits (four) as a result of inadequate knowledge on the essential aspect of these visits by the adolescent mothers [26]. The average number of ANC visits in this study was two. Teenage pregnancies are usually unplanned and unwanted [27] hence the young mother may have increased psychosocial stress to focus on pregnancy monitoring and the possible outcomes of the pregnancy.

This study revealed that low parity was associated with the need for obstetric blood transfusion. This result was contrary to findings by Eyelade and colleagues who reported that the need for blood transfusion rates increased with increasing parity [28]. The difference could be due to the latter study using a larger sample size when compared to the one used in this study. However, a study on risk factors for blood transfusion in Finland noted that primiparity predisposed women to blood transfusion [29]. Low parity which is usually associated with younger age, can result in increased blood loss due to tearing of the premature tissues of the birth canal [30].

The literature review showed varying rates and reasons for referral of obstetrics patients from peripheral to tertiary health facilities [31, 32]. This is mainly due to the different clinical criteria used for transferring and admitting patients, as well as distance traveled [33]. It was noted that the majority of participants in this study delivered by cesarean section at the two central hospitals despite having provincial and district hospitals which are supposed to be equipped to carry out the procedure. Ghardallou and colleagues also observed that lower level health facilities in Tunisia still referred patients with obstetric complications in spite of the improvement of peripheral facilities. This could be attributed to poor technical ability [5], lack of qualified staff resulting in the poor quality of care at the peripheral health care center, and poor quality of antenatal follow-up [34]. About $81.6 \%$ of the referred patients had referral notes, a percentage higher than findings by Moakoh-Coleman et al. (2019) in the Greater Accra Region in Ghana where they cited that $37.8 \%$ of the referred patients had 
Table 3 Sociodemographic factors associated with pregnancy-related outcomes

\begin{tabular}{|c|c|c|c|c|c|}
\hline \multirow[t]{2}{*}{ Variable } & \multirow[t]{2}{*}{ Characteristic } & \multicolumn{2}{|c|}{ Need for blood transfusion } & \multirow[t]{2}{*}{ OR $(95 \% \mathrm{Cl})$} & \multirow[t]{2}{*}{$p$-value } \\
\hline & & Yes $(n=32)$ & No $(n=174)$ & & \\
\hline \multirow[t]{2}{*}{ Age (completed years) } & $<20$ & 10 & 32 & $2.07(0.87-4.67)$ & 0.10 \\
\hline & $\geq 20$ & 22 & 142 & & \\
\hline \multirow[t]{2}{*}{ Marital status } & Married & 31 & 158 & $3.14(0.40-24.55)$ & 0.28 \\
\hline & Unmarried & 1 & 16 & & \\
\hline \multirow[t]{2}{*}{ Parity } & 0 & 18 & 51 & $3.10(1.43-6.70)$ & $0.004^{*}$ \\
\hline & $\geq 1$ & 14 & 123 & & \\
\hline \multirow[t]{2}{*}{ Formal education (years in school) } & $0-7$ & $4^{\mathrm{a}}$ & 56 & $0.30(0.10-0.90)$ & 0.03 \\
\hline & $>7$ & 28 & 118 & & \\
\hline \multirow[t]{4}{*}{ Religion } & Apostolic & 8 & 37 & $1.23(0.51-2.97)$ & 0.64 \\
\hline & Other & 24 & 137 & & \\
\hline & & \multicolumn{2}{|c|}{ Needed Intensive care admission } & & \\
\hline & & Yes $(n=11)$ & No $(n=195)$ & & \\
\hline \multirow[t]{2}{*}{ Age (completed years) } & $<20$ & 2 & 40 & $0.86(0.18-4.14)$ & 0.85 \\
\hline & $\geq 20$ & 9 & 155 & & \\
\hline \multirow[t]{2}{*}{ Marital status } & Married & 10 & 179 & $0.89(0.11-7.43)$ & 0.92 \\
\hline & Unmarried & 1 & 16 & & \\
\hline \multirow[t]{2}{*}{ Parity } & 0 & 5 & 64 & $1.71(0.50-5.80)$ & 0.39 \\
\hline & $\geq 1$ & 6 & 131 & & \\
\hline \multirow[t]{2}{*}{ Formal education (years in school) } & $0-7$ & 8 & 52 & $7.33(1.87-28.70)$ & 0.004 \\
\hline & $>7$ & $3^{\mathrm{a}}$ & 143 & & \\
\hline \multirow[t]{4}{*}{ Religion } & Apostolic & 1 & 44 & $0.34(0.043-2.76)$ & 0.31 \\
\hline & Other & 10 & 151 & & \\
\hline & & Perinatal outc & & & \\
\hline & & Dead $(n=46)$ & Alive $(n=160)$ & & \\
\hline \multirow[t]{2}{*}{ Age (completed years) } & $<20$ & 19 & 23 & $4.19(2.01-8.74)$ & $0.0001^{*}$ \\
\hline & $\geq 20$ & 27 & 137 & & \\
\hline \multirow[t]{2}{*}{ Marital status } & Married & 40 & 149 & $0.49(0.17-1.41)$ & 0.19 \\
\hline & Unmarried & 6 & 11 & & \\
\hline \multirow[t]{2}{*}{ Parity } & 0 & 17 & 52 & $1.22(0.61-2.41)$ & 0.57 \\
\hline & $\geq 1$ & 29 & 108 & & \\
\hline \multirow[t]{2}{*}{ Formal education (years in school) } & $0-7$ & 10 & 50 & $0.61(0.28-1.33)$ & 0.21 \\
\hline & $>7$ & 36 & 110 & & \\
\hline \multirow[t]{4}{*}{ Religion } & Apostolic & 12 & 33 & $1.36(0.63-2.91)$ & 0.43 \\
\hline & Other & 34 & 127 & & \\
\hline & & Maternal outc & & & \\
\hline & & Dead $(n=9)$ & Alive $(n=197)$ & & \\
\hline \multirow[t]{2}{*}{ Age (completed years) } & $<20$ & 2 & 40 & $1.12(0.22-5.61)$ & 0.89 \\
\hline & $\geq 20$ & 7 & 157 & & \\
\hline \multirow[t]{2}{*}{ Marital status } & Married & $3^{\mathrm{a}}$ & 14 & $6.82(1.54-30.22)$ & 0.01 \\
\hline & Unmarried & 6 & 191 & & \\
\hline \multirow[t]{2}{*}{ Parity } & 0 & 3 & 66 & $0.99(0.24-4.09)$ & 0.99 \\
\hline & $\geq 1$ & 6 & 131 & & \\
\hline Formal education (years in school) & $0-7$ & 5 & 55 & $3.23(0.84-12.46)$ & 0.09 \\
\hline
\end{tabular}


Table 3 Sociodemographic factors associated with pregnancy-related outcomes (Continued)

\begin{tabular}{|c|c|c|c|c|c|}
\hline & $>7$ & 4 & 142 & & \\
\hline \multirow[t]{2}{*}{ Religion } & Apostolic & 1 & 44 & $0.43(0.053-3.57)$ & 0.44 \\
\hline & Other & 8 & 153 & & \\
\hline
\end{tabular}

${ }^{*} p$-value $<0.05$, result is statistically significant; ${ }^{a}$ cell contents less $<5$, Chi-square test may not be valid; OR Odds Ratio, $\mathrm{Cl}$ Confidence interval

referral notes [35]. The high proportion of the availability of referral notes in this study is commendable although it can still be improved by giving feedback to lower levels of care. It is worth noting that this study did not investigate the completeness of the referral notes which is a key component towards the provision of comprehensive care. Future scientific inquiries into the completeness of referral notes can aid in determining whether the referring health workers understand the operations of the referral system.

The proportion of stillbirths in this study was high (10.7\%) when compared to findings from a Tunisian study (1.8\%) [33] but lower when compared to a similar study in Nigeria (16.4\%) [36]. This is a reflection of the deteriorated healthcare services in Zimbabwe and other sub-Saharan countries which persistently report low or stagnant coverages of effective interventions recommended for maternal, neonatal, and child health [37]. Contrary to Patel et al.'s reported findings in which most of the pregnancy-related referrals were due to obstructed or prolonged labor [38], this study noted that the major reasons for transferring patients were previous cesarean section and hypertensive disorders of pregnancy. Referring patients with previous cesarean section was mainly due to an understanding that a third to half of cesarean surgeries are performed due to a history of cesarean delivery $[39,40]$. This type of surgery cannot be performed at the primary and most secondary healthcare facilities in Zimbabwe due to the lack of skilled staff and equipment. Hypertensive disorders were also found to be the major causes of referral in other studies [4144]. The researchers of the present study noted that $38 \%$ of the women were referred during antenatal, $41.3 \%$ during the intrapartum, and $18 \%$ during the post-partum periods. An intrapartum transfer of $41.3 \%$ was high when compared to other studies in better developed countries like New Zealand (12.6\%) [32], Australia (13.2\%) [45], Denmark (11.6\%) [46] and England (between 16.7 and 20\%) [47]. Developing countries often experience a dearth of fundamental skills and equipment needed for early diagnosis of pregnancy complications and in some cases, these services could be out of reach particularly for the economically disadvantaged living in the rural areas. However, the proportion of women who were referred during the post-partum phase (18\%) compared most closely with other studies which reported (16.4\%) [46], (16.8\%) [45] and (19.6\%) [48].
Timely antenatal booking can ensure early identification and appropriate management of mothers at risk or with complicated pregnancies. The present study showed that $87 \%$ of the referred patients had been registered for pregnancy monitoring with a health facility, a proportion higher than findings of a similar study in India where they noted that $72 \%$ of the referred pregnant women were booked [38]. The WHO recommends that all pregnant women should be booked. Our ANC booking findings compared well with another local study which reported a high ANC attendance rate of $94 \%$ by women in rural Gutu District, Zimbabwe [49]. The high number of pregnancy booking could be mainly due to the versatile programs by the Ministry of Health and Child Care and non-governmental organization partners to promote free ANC booking and institutional deliveries performed by a skilled birth attendant in Government rural clinics. The emphasis on the importance of booking and attending ANC visits was highlighted in this study by having mothers who did not attend ANC being 2.5 times more likely to have negative perinatal outcomes. The messages targeting safe motherhood should therefore be sustained if the maternal and perinatal mortality rates are to be reduced in Zimbabwe.

In Zimbabwe, the rural districts have a cesarean section rate of $2.2 \%$ [50] which is way below the $5-15 \%$ recommended by the WHO [51]. Contrary to the low cesarean section rates in rural Zimbabwe, urban districts met the WHO minimum cesarean section targets of $5 \%$. Approximately $61.7 \%$ delivered by a cesarean section which is higher than $32.7 \%$ reported in a similar study [52]. It is important to note that most cases traveled long distances to access obstetric care at the two central hospitals thus, their condition may have deteriorated along the way prompting the need for urgent obstetric intervention. Low cesarean section and operative delivery rates in rural areas could also be attributed to lack of trained personnel and possible reluctance to perform vacuum deliveries thus leading to high perinatal mortality rates [52]. Obstetric hemorrhage is a life-threatening condition with post-partum hemorrhage being the most common cause of maternal morbidity and mortality [53]. Our study findings showed that $15.5 \%$ of the mothers who were transferred to Harare Central Hospital and Parirenyatwa Group of Hospitals required blood transfusion. This was slightly elevated when compared with a Nigerian study which reported an overall 
Table 4 Health system factors associated with pregnancy-related outcomes

\begin{tabular}{|c|c|c|c|c|c|}
\hline \multirow[t]{2}{*}{ Variable } & \multirow[t]{2}{*}{ Characteristic } & \multicolumn{2}{|c|}{ Need for blood transfusion } & \multirow[t]{2}{*}{ OR $(95 \% \mathrm{Cl})$} & \multirow[t]{2}{*}{$p$-value } \\
\hline & & Yes $(n=32)$ & No $(n=174)$ & & \\
\hline \multirow[t]{2}{*}{ Reasons for referral } & Previous C/S & 5 & 37 & $0.75(0.27-2.08)$ & 0.58 \\
\hline & Other & 27 & 137 & & \\
\hline \multirow[t]{2}{*}{ Duration of the journey (hours) } & $>2$ & 11 & 39 & $1.81(0.81-4.08)$ & 0.15 \\
\hline & $\leq 2$ & 21 & 135 & & \\
\hline \multirow[t]{2}{*}{ Distance (km) } & $>100$ & 27 & 100 & $4.0(1.47-10.87)$ & $0.007^{*}$ \\
\hline & $\leq 100$ & 5 & 74 & & \\
\hline \multirow[t]{2}{*}{ Stage of referral } & Partum (Intra and post) & 18 & 104 & $0.97(0.44-2.13)$ & 0.93 \\
\hline & Antenatal & 12 & 67 & & \\
\hline \multirow[t]{2}{*}{ Antenatal booking } & No & 8 & 18 & $2.89(1.13-7.37)$ & $0.03^{*}$ \\
\hline & Yes & 24 & 156 & & \\
\hline \multirow[t]{4}{*}{ Place of delivery } & Other & 12 & 32 & $2.66(1.18-6.0)$ & $0.018^{*}$ \\
\hline & Central hospital & 20 & 142 & & \\
\hline & & \multicolumn{2}{|c|}{ Needed Intensive Care admission } & & \\
\hline & & Yes $(n=11)$ & No $(n=195)$ & & \\
\hline \multirow[t]{2}{*}{ Reasons for referral } & Previous C/S & $2^{\mathrm{a}}$ & 40 & $0.78(0.16-3.76)$ & 0.76 \\
\hline & Other & 9 & 155 & & \\
\hline \multirow[t]{2}{*}{ Duration of the journey (hours) } & $>2$ & 4 & 46 & $1.85(0.52-6.61)$ & 0.34 \\
\hline & $\leq 2$ & 7 & 149 & & \\
\hline \multirow[t]{2}{*}{ Distance (km) } & $>100$ & 8 & 119 & $1.70(0.44-6.62)$ & 0.44 \\
\hline & $\leq 100$ & 3 & 76 & & \\
\hline \multirow[t]{2}{*}{ Stage of referral } & Partum (Intra and post) & 9 & 118 & $2.94(0.62-13.96)$ & 0.18 \\
\hline & Antenatal & 2 & 77 & & \\
\hline \multirow[t]{4}{*}{ Antenatal booking } & No & 1 & 25 & $0.68(0.083-5.54)$ & 0.72 \\
\hline & Yes & 10 & 170 & & \\
\hline & & Perinatal outc & & & \\
\hline & & Dead $(n=46)$ & Alive $(n=160)$ & & \\
\hline \multirow[t]{2}{*}{ Reasons for referral } & Previous C/S & 11 & 31 & $1.31(0.60-2.86)$ & 0.50 \\
\hline & Other & 35 & 129 & & \\
\hline \multirow[t]{2}{*}{ Duration of the journey (hours) } & $>2$ & 13 & 37 & $1.31(0.63-2.74)$ & 0.47 \\
\hline & $\leq 2$ & 33 & 123 & & \\
\hline \multirow[t]{2}{*}{ Distance (km) } & $>100$ & 34 & 93 & $2.04(0.98-4.23)$ & 0.055 \\
\hline & $\leq 100$ & 12 & 67 & & \\
\hline \multirow[t]{2}{*}{ Stage of referral } & Partum (Intra and post) & 24 & 98 & $0.89(0.44-1.80)$ & 0.75 \\
\hline & Antenatal & 17 & 62 & & \\
\hline \multirow[t]{2}{*}{ Antenatal booking } & No & 10 & 16 & $2.5(1.05-5.97)$ & $0.04^{*}$ \\
\hline & Yes & 36 & 144 & & \\
\hline \multirow[t]{4}{*}{ Place of delivery } & Other & 17 & 27 & $2.89(1.39-5.98)$ & $0.0043^{*}$ \\
\hline & Central hospital & 29 & 133 & & \\
\hline & & Maternal outc & & & \\
\hline & & Dead $(n=9)$ & Alive $(n=197)$ & & \\
\hline \multirow[t]{2}{*}{ Reasons for referral } & Previous C/S & 5 & 37 & $5.41(1.38-21.11)$ & 0.02 \\
\hline & Other & $4^{\mathrm{a}}$ & 160 & & \\
\hline Duration of journey (hours) & $>2$ & 2 & 48 & $0.89(0.18-4.41)$ & 0.88 \\
\hline
\end{tabular}


Table 4 Health system factors associated with pregnancy-related outcomes (Continued)

\begin{tabular}{|c|c|c|c|c|c|}
\hline & $\leq 2$ & 7 & 149 & & \\
\hline \multirow[t]{2}{*}{ Distance (km) } & $>100$ & 6 & 121 & $1.26(0.31-5.17)$ & 0.75 \\
\hline & $\leq 100$ & 3 & 76 & & \\
\hline \multirow[t]{2}{*}{ Stage of referral } & Partum (Intra and post) & 2 & 120 & $0.25(0.047-1.30)$ & 0.1 \\
\hline & Antenatal & 5 & 74 & & \\
\hline \multirow[t]{2}{*}{ Antenatal booking } & No & 5 & 21 & $10.48(2.61-42.08)$ & 0.0009 \\
\hline & Yes & $4^{a}$ & 176 & & \\
\hline \multirow[t]{2}{*}{ Place of delivery } & Other & 4 & 40 & $3.14(0.81-12.23)$ & 0.1 \\
\hline & Central hospital & 5 & 157 & & \\
\hline
\end{tabular}

${ }^{*} p$-value $<0.05$, result is statistically significant; ${ }^{a}$ cell contents less $<5$, Chi-square test may not be valid; OR Odds Ratio, $\mathrm{Cl}$ Confidence interval, $\mathrm{C} / \mathrm{S}$ Cesarean section

obstetric blood transfusion rate of $12.1 \%$ [54]. The difference in blood transfusion rates could be explained by having the present study focusing on urgent complicated obstetric cases observed over a shorter period of 3 months while Anorlu and others conducted their study over a three-year period. Mothers who traveled more than $100 \mathrm{~km}$ were 4 times more likely to be transfused than those who traveled fewer kilometers and mothers who delivered at the rural facility or on transit were 2.66 times more likely to be transfused. Nearly two-thirds of the referred patients had a cesarean section which is a procedure that carries a risk of major intra-operative blood loss because the majority of maternal deaths occur as a consequence of post-partum hemorrhage associated with cesarean section [55].

The present study revealed that 5.3\% required ICU admission for hemorrhage or hypertensive related complications. This proportion was higher than the one documented in a study by Jamal et al., 2018 (1.3\%) [56] and the higher rates observed in this study may be due to the persistent limited supply of blood for transfusion at primary and secondary health care centers in Zimbabwe hence they transfer critically ill patients to tertiary care facilities.

There were nine maternal deaths $(\mathrm{CFR}=4.4 \%)$ during the 3 months of the study period and this frequency was very high when compared to other studies which reported no deaths over 3 months [33] and 13 deaths over 4 years [38]. UNICEF/WHO/UNFPA recommend a maximum acceptable CFR of less than 1\% [57]. The CFR in this study was higher than the recommended level because some patients traveled for long distances to reach the central hospitals and this may also be due to the three delays. The perinatal mortality rate was 151/ 1000 live births which was high when compared to findings from a similar study in India (95.23/1000 live births) [44]. Traveling long distances can increase the chances of fetal distress thereby increasing the possibility of intrauterine death. However, this study did not ascertain the actual obstetric events leading to maternal and perinatal deaths and investigators recommend future inquiry into these two public health challenges.

When compared with urban pregnant women, mothers who dwell in rural regions often face considerable limitations when it comes to utilization of obstetric care services. Many developing countries do not have resources to fully equip rural facilities at the same extend as the urban facilities [58]. Furthermore, there is little demand for equal access for emergency obstetric care by the rural women due to limited education when compared to urban women. Geographical accessibility and transport availability are often poor in rural areas when compared to urban setting where private and public transport is available and sufficiently affordable to mothers seeking health care. High population densities in urban areas also enhance geographical proximity of healthy facilities when compared to the sparsely populated rural settings [58].

\section{Limitations}

The present study only included those women who were referred from rural facilities and managed to arrive at the central hospitals. Women who were referred but failed to arrive at the central hospitals because of failure to secure transport or dying in transit were not included thus, the number of such patients is not known. Interviewing the health workers at primary and secondary facilities could have exposed the actual reasons for referring patients and assisted in relating these to the maternal outcomes but this was not done due to financial constraints on the part of researchers. The authors recommend a follow-up qualitative study to understand the health workers' perspective on the operations of the patient referral system.

\section{Conclusion}

Obstetric complications of maternal referrals from rural facilities to the central hospitals were associated with adverse maternal and perinatal outcomes. The proportion of obstetric patients being referred to tertiary institutions 
reveals how primary and secondary healthcare facilities in Zimbabwe are falling short of offering the services they should be offering. Equipping these facilities with skilled human resources as well as contemporary equipment could help decongest the central hospitals consequently reducing the maternal and perinatal mortality rates caused by delays that occur when the patients are transferred to higher levels of care.

\section{Abbreviations}

ANC: Antenatal Clinic; CFR: Case fatality rate; ICU: Intensive care unit; LMICS: Low and middle-income countries; MMR: Maternal mortality rate; WHO: World Health Organization

\section{Acknowledgments}

The authors are grateful to the staff at Harare Central Hospital and Parirenyatwa Group of Hospitals who took part in the study. The authors would also like to thank the study participants whose input was invaluable to the success of this work.

\section{Authors' contributions}

WB came up with the concept, wrote the protocol, and collected the data. PM analyzed the data and wrote the first manuscript draft. Both WB and PM reviewed the manuscript and made essential adjustments. All authors read and approved the final manuscript.

\section{Funding}

None.

\section{Availability of data and materials}

The datasets used and/or analyzed during the current study are available from the corresponding author on reasonable request.

\section{Declarations}

\section{Ethics approval and consent to participate}

The protocols were carried out in accordance with the Medical Research Council of Zimbabwe guidelines and regulations. A written informed consent was obtained from all participants of the study. Permission to carry out the study was sought and obtained from Harare Central Hospital and Parirenyatwa Group of Hospital authorities while ethical clearance was obtained from The Joint Research Ethics Committee and Medical Research Council of Zimbabwe (Reference number: MRCZ/B/1378).

\section{Consent for publication}

Not Applicable.

\section{Competing interests}

Authors declare that they have no competing interests

\section{Author details}

${ }^{1}$ Faculty of Medicine and Health Sciences, University of Zimbabwe, Harare, Zimbabwe. ${ }^{2}$ Ministry of Health and Child Care, Bulawayo, Zimbabwe. ${ }^{3}$ Clinical Research Centre, Africa University, 132 H. Chitepo Street, Mutare, Zimbabwe.

Received: 18 December 2020 Accepted: 16 March 2021

Published online: 25 March 2021

\section{References}

1. Alkema L, Chou D, Hogan D, Zhang S, Moller AB, Gemmill A, Fat DM, Boerma T, Temmerman M, Mathers C, Say L, United Nations Maternal Mortality Estimation Inter-Agency Group collaborators and technical advisory group. Global, regional, and national levels and trends in maternal mortality between 1990 and 2015, with scenario-based projections to 2030: a systematic analysis by the UN maternal mortality estimation inter-Agency group. Lancet. 2016;387(10017):462-74. https://doi.org/10.1016/S0140-673 6(15)00838-7.
2. World Health Organization. Trends in maternal mortality: 2000 to 2017: estimates by WHO, UNICEF, UNFPA, World Bank Group and the United Nations population division. Geneva: World Health Organization; 2019.

3. Say L, Chou D, Gemmill A, Tuncalp O, Moller AB, Daniels JD, et al. Global causes of maternal death: a WHO systematic analysis. Lancet Global Health. 2014;2(6):e323-33. https://doi.org/10.1016/S2214-109X(14)70227-X.

4. Thaddeus S, Maine D. Too far for walk: maternal mortality in context. Soc Sci Med. 1994;30:1091-110.

5. Murray SF, Pearson SC. Maternity referral systems in developing countries: current knowledge and future research needs. Soc Sci Med. 2006;62(9): 2205-15. https://doi.org/10.1016/j.socscimed.2005.10.025.

6. Austin A, Gulema H, Belizan M, Colaci DS, Kendall T, Tebeka M, Hailemariam M, Bekele D, Tadesse L, Berhane Y, Langer A. Barriers to providing quality emergency obstetric care in Addis Ababa, Ethiopia: healthcare providers' perspectives on training, referrals and supervision, a mixed methods study. BMC Pregnancy Childbirth. 2015;15(1):74. https://doi.org/10.1186/s12884-015-0493-4.

7. Koller TS. Rural poverty and health services: challenges and gaps. Expert meeting on eradicating rural poverty to implement the 2030 Agenda for Sustainable Development, Addis Ababa. 27 February to 1 March 2019. Geneva: World Health Organization; 2019. Available at: https://www.un.org/ development/desa/dspd/wp-content/uploads/sites/22/2019/03/WHO-RuralHealth_Kollert-Theadora-Swift_1March2019@06h00.pdf.

8. Jacobs C, Michelo C, Moshabela M. Why do rural women in the remote and poorest areas of Zambia predominantly attend only one antenatal care visit with a skilled provider? A qualitative inquiry. BMC Health Serv Res.. 2018; 18(409). https://doi.org/10.1186/s12913-018-3212-9.

9. Finlayson K, Downe S. Why do women not use antenatal services in lowand middle-income countries? A meta-synthesis of qualitative studies. PLoS Med. 2013;10(1):e1001373. https://doi.org/10.1371/journal.pmed.1001373.

10. Dodzo MK, Mhloyi M. Home is best: why women in rural Zimbabwe deliver in the community. PLoS One. 2017;12(8):e0181771. https://doi.org/10.1371/ journal.pone.0181771.

11. Lawson GW, Keirse MJ. Reflections on the maternal mortality millennium goal. Birth. 2013;40(2):96-102. https://doi.org/10.1111/birt.12041.

12. United Nations in Zimbabwe Issue Paper Series. Maternal Mortality in Zimbabwe. Evidence, Costs and Implications Periodic Publications. United Nations Zimbabwe. 2013;1. Available at: http://www.archive.kubatana.net/ docs/demgg/unwomen_maternal_mortality_in_zim_130609.pdf.

13. Central Statistical Office (Zimbabwe) and Macro International Inc. Zimbabwe Demographic and Health Survey 1999. Calverton: Central Statistical Office and Macro International Inc:; 2000.

14. Ministry of Health and Child Welfare. National Maternal and Perinatal Mortality Survey, 2009. Harare: Government of Zimbabwe; 2009.

15. Zimbabwe National Statistics Agency (ZIMSTAT). Multiple Indicator Survey 2014, Final Report. Harare: Zimbabwe; 2015. Available at: https://zimbabwe. savethechildren.net/sites/zimbabwe.savethechildren.net/files/library/Zimba bwe\%20Multiple\%20Indicator\%20Cluster\%20Survey\%202014.pdf.

16. Zimbabwe National Statistics Agency and ICF International. Zimbabwe Demographic and Health Survey 2015: Key Indicators. Rockville: Zimbabwe National Statistics Agency (ZIMSTAT) and ICF International; 2016.

17. Zimbabwe National Statistics Agency (ZIMSTAT). Zimbabwe Census 2012 Preliminary Report, Harare, Zimbabwe: ZIMSTAT. 2012. Available at: https:// unstats.un.org/unsd/demographic-social/census/documents/Zimbabwe/ ZWE_CensusPreliminary2012.pdf.

18. Training and Research Support Centre and Ministry of Health and Child Care, Zimbabwe. Zimbabwe Equity Watch 2014, TARSC, MoHCC, EQUINET Harare. 2014. Available at: https://www.equinetafrica.org/sites/default/files/ uploads/documents/Zimbabwe_EW_2014.pdf.

19. Nyakatawa GT, Madzimbamuto FD, Shumbairerwa S, Chikumba E. How inadequate availability of drugs affects anesthesia practice in low resource setting. Int Anest Res Soc. 2016;123(3):755.

20. Mangundu M, Roets L, Van Rensberg EJ. Accessibility of healthcare in rural Zimbabwe: the perspective of nurses and healthcare users. Afr J Prim Health Care Fam Med. 2020;12(1):a2245.

21. Majoko F, Nystrom L, Munjanja SP, Lindmark G. Effectiveness of referral systems for antenatal and intra-partum problems in Gutu district, Zimbabwe. J Obstet Gynaecol. 2005;25(7):651-61.

22. Silva AL, Mendes Ada C, Miranda GM, Sa DA, Souza WV, Lyra TM. Evaluation of maternal and neonatal hospital care: quality index of completeness. Revista de saude publica. 2014;48(4):682-91. https://doi.org/10.1590/500348910.2014048004605. 
23. Pembe AB, Carlstedt A, Urassa DP, Lindmark G, Nystrom L, Darj E. Effectiveness of maternal referral system in a rural setting: a case study from Rufiji District, Tanzania. BMC Health Serv Res. 2010;10(1):326. https://doi. org/10.1186/1472-6963-10-326.

24. Abebe AM, Fitie GW, Jember DA, Reda MM, Wake GE. Teenage pregnancy and its adverse obstetric and perinatal outcomes at Lemlem Karl Hospital, Tigray, Ethiopia, 2018. Biomed Res Int. 2020;3124847:8.

25. Ganchimeg T, Ota E, Morisaki N, Laopaiboon M, Lumbiganon P, Zhang J, Yamdamsuren B, Temmerman M, Say L, Tunçalp Ö, Vogel JP, Souza JP, Mori $\mathrm{R}$, on behalf of the WHO Multicountry Survey on Maternal Newborn Health Research Network. Pregnancy and childbirth outcomes among adolescent mothers: a World Health Organization multi-country study. BJOG. 2014; 121(1):40-8. https://doi.org/10.1111/1471-0528.12630.

26. Mekonnen T, Dune T, Perz J. Maternal health service utilization of adolescent women in sub-Saharan Africa: a systematic scoping review. BMC Pregnancy and Childbirth. 2019;19(366).

27. Christofides NJ, Jewkes RK, Dunkle KL, McCarty F, Shai NJ, Nduna M, Sterk C. Risk factors for unplanned and unwanted teenage pregnancies occurring over two years of follow-up among a cohort of young south African women. Glob Health Action. 2014;7(1):23719. https://doi.org/10.3402/gha.v7.23719.

28. Ayelade OR, Adesina OA, Adewole IF, Adebowale SA. Blood transfusion requirement during caesarean delivery: risk factors. Ann Ibadan Postgrad Med. 2015;13(1):29-35.

29. Jakobsson M, Gissler M, Tapper A. Risk factors for blood transfusion at delivery in Finland. Acta Obstet Gynecol Scand. 2013;92(4):414-20. https:// doi.org/10.1111/j.1600-0412.2012.01490.x.

30. Kozuki N, Lee ACC, Silveira MF, Sania A, Vogel JP, Adair L, Barros F, Caulfield LE, Christian P, Fawzi W, Humphrey J, Huybregts L, Mongkolchati A, Ntozini R, Osrin D, Roberfroid D, Tielsch J, Vaidya A, Black RE, Katz J, Child Health Epidemiology Reference Group (CHERG) Small-for-Gestational-Age-Preterm Birth Working Group. The associations of parity and maternal age with small-for-gestational-age, preterm, and neonatal and infant mortality: a meta-analysis. BMC Public Health. 2013;13(Suppl 3):S2. https://doi.org/10.11 86/1471-2458-13-S3-S2.

31. Hutchinson FH, Davies MW. Time-to-delivery after maternal transfer to a tertiary perinatal Centre. Biomed Res Int. 2014;2014:325919.

32. Grigg CP, Tracy SK, Tracy M, Schmied V, Monk A. Transfer from primary maternity unit to tertiary hospital in New Zealand - timing, frequency, reasons, urgency and outcomes: part of the evaluating maternity units study. Midwifery. 2015;31(9):879-87. https://doi.org/10.1016/j.midw.2015.04.018.

33. Ghardallou M, Limam M, Khelifi A, Khairi O, Khairi $H$, Mtiraoui A, et al. Obstetrics referrals to a tertiary care maternity: a descriptive study. PanAfrican Medical Journal. 2019;33:306

34. Baldé IS, Diallo FB, Diallo Y, Diallo A, Diallo MH, Camara MK et al. [Intrapartum obstetrical transfers: socio-demographic, clinical and prognostic aspects in Conakry, Guinea]. Med Trop (Mars). 2011;71(6):628-9.

35. Moakoh-Coleman M, Arhinful DK, Klipstein-Grobusch K, Ansah E, Koram KA. Coverage of intermittent preventive treatment of malaria in pregnancy (IPTp) influences delivery outcomes among women with obstetric referrals at the district level in Ghana. Malaria J. 2020;19(222). https://doi.org/10.1186/ s12936-020-03288-4.

36. Akaba GO, Ekele BA. Maternal and fetal outcomes of emergency obstetric referrals to a Nigerian teaching hospital. Trop Dr https://doi.org/10.1177/004 9475517735474. 2017

37. Haley CA, Vermund SH, Moyo P, Kipp AM, Madzima B, Kanyowa T. Impact of a critical health workforce shortage on child health in Zimbabwe: a country case study on progress in child survival, 2000-2013. Health Policy Plan. 2017; 32(5):613-24. https://doi.org/10.1093/heapol/czw162.

38. Patel AB, Prakash AA, Raynes-Greenow C, Pusdekar YV, Hibberd PL. Description of inter-institutional referrals after admission for labor and delivery: a prospective population based cohort study in rural Maharashtra, India. BMC Health Serv Res. 2017;17(1):360. https://doi.org/10.1186/s12913-017-2302-4.

39. Denham SH, Humphrey T, deLabrusse C, Dougall N. Mode of birth after a caesarean section: individual prediction scores using Scottish population data. BMC Pregnancy Childbirth. 2019;19(1):84. https://doi.org/10.1186/s12 884-019-2226-6.

40. Wingert A, Johnson C, Featherstone R, Sebastianski M, Hartling L, Douglas WR. Adjunct clinical interventions that influence vaginal birth after caesarean rates: a systematic review. BMC Pregnancy Childbirth. 2018;18(1): 452. https://doi.org/10.1186/s12884-018-2065-x.
41. Khatoon A, Hasny SF, Irshad S, Ansari J. An audit of obstetrics referrals to Abbasi Shaheed hospital. Pak J Surg. 2011;27(4):304-3089.

42. Charu R, Kamal G, Neelu S. Review of Referred Obstetric Cases-Maternal and Perinatal Outcome. Bombay Hosp J. 2010;52(1):52-6.

43. Jahn A, V VB. Referral in pregnancy and childbirth: concept and strategies. Stud Health Serv Organ Policy 2001;17:229-246.

44. Dutta I, Roy P, Dasgupta S, Khan M, Saha P. Obstetrics referrals: maternal and perinatal outcome in medical college hospital in eastern India. Indian J Obstet Gynecol Res. 2020;7(1):91-9.

45. Monk A, Tracy M, Foureur M, et al. Evaluating midwifery units (EMU): a prospective cohort study of freestanding midwifery units in New South Wales, Australia. BMJ Open. 2014;4:1-11

46. Overgaard $\mathrm{C}$, Moller $\mathrm{A}$, Fenger-Gron $\mathrm{M}$, et al. Free standing midwifery unit versus obstetric unit: a matched cohort study of outcomes in low-risk women. BMJ Open. 2011;2:1-11.

47. Rowe R, Fitzpatrick R, Hollowell J, Kurinczuk JJ. Transfers of women planning birth in midwifery units: data from the birthplace prospective cohort study. BJOG. 2012;119(9):1081-90. https://doi.org/10.1111/j.1471-0528.2012.03414.x.

48. Patterson J, Foureur M, Skinner J. Patterns of transfer in labour and birth in rural New Zealand. Rural Remote Health. 2011;11:17101-15.

49. Nilses C, Nyström L, Munjanja S, Lindmark G. Self-reported reproductive outcome and implications in relation to use of care in women in rural Zimbabwe. Acta Obstet Gynecol Scand. 2002;81(6):508-15. https://doi.org/1 0.1034/j.1600-0412.2002.810606.x.

50. Guzha BT, Magwali TL, Mateveke B, Chirehwa M, Nyandoro G, Munjanja SP. Assessment of quality of obstetric care in Zimbabwe using the standard primipara. BMC Pregnancy Childbirth. 2018;18(205). https://doi.org/10.1186/ s12884-018-1863-5.

51. Chalmers B, Mangiaterra $V$, Porter R. World health organization principles of perinatal care: the essential antenatal, perinatal and postpartum care course. Birth. 2001;28(3):202-7. https://doi.org/10.1046/j.1523-536x.2001.00202.x.

52. Sorbye IK, Vangen $\mathrm{S}$, Oneko $\mathrm{O}$, et al. Caesarean section among referred and self-referred birthing women: a cohort study from a tertiary hospital, northeastern Tanzania. BMC Pregnancy Childbirth. 2011;11(55).

53. Sørbye IK, Vangen S, Oneko O, Sundby J, Bergsjø P. Caesarean section among referred and self-referred birthing women: a cohort study from a tertiary hospital, northeastern Tanzania. BMC Pregnancy Childbirth. 2011; 11(55). https://doi.org/10.1186/1471-2393-11-55.

54. Anorlu RI, Orakwe CO, Abudu OO, Akanmu AS. Uses and misuse of blood transfusion in obstetrics in Lagos, Nigeria. West Afri J Med. 2003;22:124-7.

55. Waterston M, Wolfe C, Hooper R, Bewley S. Postnatal morbidity after childbirth and severe obstetric morbidity. Br J Obstet Gynecol. 2003;110:728-33.

56. Jamal S, Mehta A, Goel N, Ahuja M, Afreen N, Malik S. Obstetrics ICU admissions: challenges faced at a tertiary referral Centre. Int J Reprod Contracept Obstet Gynecol. 2018;7(5):1840-3. https://doi.org/10.18203/232 0-1770.ijrcog20181914.

57. Measure Evaluation. Family Planning and Reproductive Health Indicators Database. Case Fatality Rate (CFR)- all complications. Available at https:// www.measureevaluation.org/prh/rh_indicators/womens-health/sm/case-fata lity-rate-cfr-all-complications\# Accessed 22 Nov 2020.

58. Munjanja SP, Magure T, Kandawasvika G. Geographical access, transport and referral systems. Maternal and Perinatal Health in Developing Countries. Eds J Hussein, A. McCaw-Binns and R. Webber. 2012:139-154.

\section{Publisher's Note}

Springer Nature remains neutral with regard to jurisdictional claims in published maps and institutional affiliations.

\section{Ready to submit your research? Choose BMC and benefit from:}

- fast, convenient online submission

- thorough peer review by experienced researchers in your field

- rapid publication on acceptance

- support for research data, including large and complex data types

- gold Open Access which fosters wider collaboration and increased citations

- maximum visibility for your research: over $100 \mathrm{M}$ website views per year

At BMC, research is always in progress.

Learn more biomedcentral.com/submissions 